\title{
Analisis Teknik dan Tekno Ekonomi \\ Pengusahaan Minyak Kayu Putih sebagai Alternatif Pasca Panen Skala Produksi Desa Cikembang Kecamatan Kertasari \\ Technical and Techno-Economic Analysis of Eucalyptus Oil Exploitation as Post- Harvest Alternative at the Production Scale of Cikembang Village, Kertasari District
}

\author{
Andis Priswantoro ${ }^{a, b^{*}}$, Nana Sulaksana ${ }^{a, c^{*}}$, Cipta Endyanaa,c,d \\ dan Anggoro Tri Mursito ${ }^{*}$ \\ ${ }^{a}$ Sekolah Pascasarjana, Program Studi Inovasi Regional, Universitas Padjadjaran Bandung, \\ Jl. Dipati Ukur No. 35, Bandung \\ ${ }^{b} B P K-L I P I$ \\ cFakultas Teknik Geologi, Universitas Padjadjaran Bandung \\ ${ }^{d}$ Pusat Riset Citarum Harum, Universitas Padjadjaran Bandung \\ ePusat Penelitian Geoteknologi LIPI, Bandung
}

\section{Riwayat Naskah:}

Diterima 92021

Direvisi 122021

Disetujui 122021

\begin{abstract}
ABSTRAK: Tujuan penelitian untuk menganalisis kelayakan pengusahaan penyulingan minyak kayu putih (MKP) di Desa Cikembang apakah dapat memberikan alternatif pasca panen dengan memberikan kontribusi ekonomi skala produksi. Mesin penyulingan MKP terpasang dengan sistem steam/uap di Kecamatan Kertasari memiliki standar peralatan mesin penyulingan yang dapat mendukung MKP bermutu sesuai SNI. Distilasi skala laboratorium dihasilkan tetesan pertama pada 3 jam pertama. Warna jernih sesuai spesifikasi warna standar minyak atsiri kayu putih berwarna jernih, untuk bau minyak yang dihasilkan khas bau kayu putih dan bobot jenis $0,913 \mathrm{~g} / \mathrm{ml}$ masuk dalam spesifikasi standar rentang bobot jenis yang dipersyaratkan 0,900 - 0,930 g/ml. Analisis tekno ekonomi ditunjukkan bahwa pengusahaan MKP layak dijalankan dengan beberapa parameter yaitu NPV sebesar Rp. 323.302.615,-; nilai IRR: 22.5\% dan pay back period (PB) 6,31 tahun atau 76 bulan. Sesuai analisis sensitivitas, pengusahaan MKP tersebut sangat sensitif terhadap parameter menurunnya jumlah produksi bahan baku MKP yaitu daun tanaman kayu putih.
\end{abstract}

Kata kunci: MKP, pasca panen, produksi, tekno ekonomi

ABSTRACT: The purpose of the study was to analyze the feasibility of using eucalyptus oil refining (MKP) in Cikembang Village, whether it can provide an alternative post-harvest by contributing to the economy of production scale. The MKP distillation machine installed with a steam system in Kertasari District has standard equipment for distilling machines that can support quality MKP according to SNI. Laboratory-scale distillation produces the first drop in the first 3 hours. The color is clear according to the standard color specifications for eucalyptus essential oil, it is clear, the smell of the oil produced is typical of the smell of eucalyptus and a specific gravity of $0.913 \mathrm{~g} / \mathrm{ml}$ is included in the standard specifications for the required specific gravity range of $0.900-0.930 \mathrm{~g} / \mathrm{ml}$. The technoeconomic analysis shows that the MKP concession is feasible to run with several parameters, namely the NPV of Rp. 323.302 .615 ,-; IRR value: $22.5 \%$ and pay back period (PB) 6.31 years or 76 months. According to the sensitivity analysis, the MKP concession is very sensitive to the parameter of decreasing the amount of production of MKP raw materials, namely the leaves of the eucalyptus plant.

Keywords: MKP, post-harvest, production, techno-economy

\footnotetext{
Kontributor utama

Email : andis.priswantoro@gmail.com; andi011@lipi.go.id; andis18002@mail.unpad.ac.id;
} 


\section{Pendahuluan}

Tanaman kayu putih (Melaleuca cajuputi) merupakan salah satu tanaman konservasi daerah aliran sungai (DAS) di Desa Cikembang. Kayu putih tanaman penghasil minyak atsiri yang penting bagi industri atsiri di Indonesia (Aryani, 2020). Kayu putih dapat memberikan keuntungan ganda pada pengembangan tanaman kayu putih sebagai konservasi serta memberikan kesempatan kerja yang memberikan implikasi penghasilan petani (Mohhamad dan Etty, 2017). Potensi tanaman kayu putih secara ekonomi melalui pemanfaatan hutan dengan dasar azas kelestarian fungsi dan azas perusahaan yang meliputi penanaman, pemeliharaan dan pengamanan, pemanenan hasil, pengolahan dan pemasaran hasil hutan (P. R. Indonesia, 1999). Hasil hutan bukan kayu (HHBK) merupakan hasil hutan hayati baik nabati maupun hewani beserta produk turunan dan budidaya, kecuali kayu yang berasal dari hutan (M. K. R. Indonesia, 2007). Produk HHBK memiliki komparatif dan paling bersinggungan dengan masyarakat sekitar hutan (Ratnaningsih, 2020).

Produk turunan minyak kayu putih sebagai bentuk pengusahaan berupa produk turunan komoditas hasil hutan bukan kayu yang dapat dihasilkan oleh kelompok hasil tumbuhan dan tanaman "Kelompok minyak atsiri". Senada dengan apa yang dikatakan Badan Pangan Dunia (FAO) yaitu hasil hutan bukan kayu, adalah hasil-hasil biologi selain kayu yang diperoleh dari hutan (Nasution, 2014). Hasil biologi minyak kayu putih dari hasil sampingan sebuah pohon yaitu daun. Daun dihasilkan dari pohon tegakan periode stabil dengan produksi maksimum terjadi pada umur tegakan 1316 tahun dengan produktivitas 12.185 $16.673 / \mathrm{kg} / \mathrm{ha} /$ tahun (Utomo et al., 2012). Tanaman obat aromatik eucalyptus dan minyak esensialnya banyak digunakan sejak jaman dahulu dalam pengobatan tradisional serta aktivitas biologis eucalyptus meningkat pesat dalam dekade terakhir (Limam, Ben, Tammar, Ksibi, Khammassi, Jallouli, et al., 2020).

Analisis teknik dan tekno ekonomi perlu dilakukan dalam pengolahan tanaman kayu putih menjadi minyak kayu putih (MKP) alternatif pasca panen skala produksi (Alamsyah \& Supriatna, 2018), serta potensi tanaman kayu putih di Indonesia cukup besar untuk dikembangkan (Behuku et al., 2016). Dikatakan pula oleh Behuku et al. (2016), bahwa perhitungan secara terukur nilai tambah ekonomis mampu memberi kontribusi nilai tambah ekonomi secara nyata. Estimasi produksi merupakan salah satu upaya mengetahui potensi ke depan untuk keberhasilan pengusahaan tanaman kayu putih secara ekonomis (Lilik Norvi Purhantanto, Projo Danoedoro, 2019).
Dalam perdagangan pasar dunia terdapat 90 jenis minyak atsiri, sementara di Indonesia tumbuh 40 jenis tanaman minyak atsiri dan 14 diantaranya menjadi komoditi ekspor (minyak sereh wangi, minyak akar wangi, minyak nilam, minyak pala, minyak daun cengkeh, minyak kenanga, minyak cendana, minyak anis/adas, minyak jahe, minyak massoi, minyak lada, minyak kayu putih, minyak daun jeruk purut dan minyak kemukus) (Ma'mun, 2015). Pasar international membuat mutu minyak atsiri Indonesia harus bersaing dengan minyak atsiri dari negara-negara lain. Dengan adanya sifat dan karakteristik bahan baku yang berbeda-beda, maka penanganan dan penyulingan minyak atsiri sangat dipengaruhi oleh beberapa faktor, seperti varietas, lingkungan tempat tumbuh, kesuburan tanah, umur panen, cara penanganan bahan dan cara penyulingannya. Di Indonesia, produksi minyak atsiri dilakukan oleh para pengrajin sebagai usaha sampingan. Umumnya pengolahan minyak atsiri di Indonesia dilakukan dengan cara destilasi. Ekstraksi/isolasi terdiri dari : (1) penyulingan (distillation), (2) pengepresan (pressing), (3) ekstraksi dengan pelarut menguap (solvenxt extraction), (4) ekstraksi dengan lemak yang tergantung dari jenis tanamannya/bahan bakunya (Rahmi, 2018).

Dilatar belakangi oleh potensi penyulingan tanaman kayu putih di Desa Cikembang menjadi minyak kayu putih (MKP) cukup besar, maka alternatif pasca panen skala produksi dapat meningkatkan kapasitas ekonomi masyarakat Desa Cikembang. Penyulingan juga dapat sinergi dengan konservasi. Berdasarkan hal tersebut, penelitian ini bertujuan untuk menganalisis teknik penyulingan minyak kayu putih (MKP) dan tekno ekonomi pengusahaan minyak kayu putih.

\section{Bahan dan Metode}

\subsection{Bahan}

Bahan yang digunakan dalam penelitian ini yaitu tanaman minyak kayu putih, bahan proses produksi Minyak Kayu Putih (MKP) penghasil daun sebagai bahan baku. Daun kayu putih (melaleuca cajuputi), aluminium foil, $\mathrm{MgSO}_{4}$ dan akuades. Data Desa Cikembang meliputi data observasi potensi skala produksi, harga bahan produksi, dan peralatan pengusahaan MKP mesin terpasang saat ini.

\subsection{Alat}

Peralatan yang digunakan penelitian ini adalah: satu unit alat destilasi, corong pemisah, timbangan manual, timbangan analitik, piknometer, dan refraktometer. Alat pendukung yang digunakan adalah alat tulis menulis, kuesioner, alat hitung 
(software Microsoft Excel), alat komunikasi (HP) dan kamera.

\subsection{Metode}

Prosedur kerja dalam penelitian sesuai proses penyulingan uap dan air (Aryani, 2020), sebagai berikut:

a. Bahan baku dan perolehannya

Bahan baku yang digunakan adalah daun tanaman kayu putih yang diperoleh dari Desa Cikembang, Kertasari, Kabupaten Bandung.

b. Proses Pengeringan dan pelayuan

Mula-mula daun kayu putih diletakkan dalam ruangan dengan sirkulasi udara yang cukup baik selama tiga hari. Pada proses pengeringan ini, daun kayu putih sesekali dibolak-balik agar merata keringnya.

c. Proses Penyulingan

Proses penyulingan dilakukan dengan metode penyulingan uap dan air (Water Steam Destilation). Langkah-langkah proses penyulingan adalah:

> Pemasangan peralatan penyulingan yang terdiri dari ketel suling, kondensor dan tungku.

> Pengisian air ke dalam ketel suling sampai permukaannya tidak jauh dari bagian bawah saringan dimana bahan diletakkan, selanjutnya bahan baku dimasukkan ke dalam ketel penyulingan.

> Penutupan ketel pada alat penyulingan dan dikaitkan dengan baut. Proses ini perlu diperhatikan jangan ada celah yang dapat menyebabkan keluarnya uap.

> Proses perebusan air sampai mendidih, uap terbentuk akan lewat melalui saringan lubang-lubang kecil dan melewati celah-celah bahan baku. Minyak atsiri dalam bahan akan ikut bersama uap panas tersebut menuju kondensor (pendingin), sehingga terjadi pengembunan (uap air dan minyak akan mengembun). Setelah 1 jam, embun keluar pada kondensor bersama-sama dengan tetesan air yang tercampur minyak. Pada ujung kondensor diletakkan Erlenmeyer guna menampung air beserta minyak yang keluar, mulut erlenmeyer ditutup menggunakan aluminium foil agar tidak terdapat celah menguapnya minyak atsiri. Penyulingan dilakukan selama 6-8 jam. Lama penyulingan dimulai saat minyak keluar pertama kali sampai minyak tidak keluar lagi.

d. Proses Pemisahan Air dan Minyak Kayu Putih Pemisahan air dan minyak atsiri menggunakan alat corong pemisah. Proses pemisahan dilakukan sesuai perbedaan bobot jenisnya.
Kemudian dilakukan penimbangan minyak untuk mengetahui beratnya.

e. Proses Pemurnian Minyak

Minyak atsiri yang diperoleh dibebaskan dari sisa air. Bahan kimia $\mathrm{MgSO}_{4}$ (magnesium sulfat) digunakan untuk proses pemurnian minyak, bahan tersebut berfungsi sebagai pengikat air dan kotoran yang masih tercampur pada minyak.

f. Menghitung Pengusahaan Minyak Kayu Putih

Metode yang digunakan yaitu menggunakan: (a) Analisis teknis pembuatan MKP (Gambar 1) dan (Gambar 2), (b) Analisis Tekno Ekonomi dengan kriteria Thompson dan Geoge (2009)(Indrajaya et al., 2013), yaitu NPV, BCR, IRR dan sensitivitas. Dengan sumber data informasi pengeluaran $(C)$ dan penerimaan $(B)$ pengusahaan pengolahan MKP sebagai dasar kelayakan finansial usahanya. NPV adalah selisih antara total penerimaan dikurangi dengan total pengeluaran yang didiskonto menggunakan faktor diskonto dalam kurun waktu tertentu (t), pada pangkat suku i, dituliskan sebagai berikut:

$$
\begin{aligned}
\mathrm{NPV} & =\sum_{\mathrm{t}=\mathbf{0}}^{\mathrm{T}} \frac{B \mathrm{t}-C \mathrm{t}}{(1+i)^{\mathrm{t}}} \ldots(1) \\
\sum_{\mathrm{t}=0}^{\mathrm{T}} \frac{B \mathrm{t}}{(1+\mathrm{i})^{\mathrm{t}}} \mathrm{d} \ldots(2) & \sum_{\mathrm{t}=\mathbf{0}}^{\mathrm{T}} \frac{C \mathrm{t}}{(1+i)^{\mathrm{t}}} \ldots(3) \\
\mathrm{BCR} & =\frac{\sum_{\mathrm{t}=0}^{\mathrm{T}} \frac{B \mathrm{t}}{(1+i)^{\mathrm{t}}} d}{\sum_{\mathrm{t}=0}^{\mathrm{T}} \frac{C \mathrm{t}}{(1+i)^{\mathrm{t}}}} \ldots(4) \\
\text { IRR }=i & +\frac{\mathrm{NPV} 1}{\mathrm{NPV} 1-\mathrm{NPV} 2} \times(i 2-i 1) \ldots(5)
\end{aligned}
$$

BCR merupakan perbandingan dari total penerimaan terdiskon selama kurun waktu proyek (2) dibagi dengan total pengeluaran terdiskon selama kurun waktu proyek (3). Nilai BCR akan memberikan gambaran estimasi pengembalian dalam rupiah dari investasi yang ditanamkan (4). IRR merupakan tingkat bunga diskonto dimana nilai NPV sama dengan nol. Hal ini berarti nilai IRR menunjukkan nilai aktual pengembalian dari suatu proyek yang dirumuskan/dituliskan (5).

Analisis finansial dilakukan untuk pengusahaan MKP sebagai alternatif pasca panen akan tanaman kayu putih dengan memperhatikan potensi daerah konservasi Desa Cikembang dan potensi pasar MKP. Analisis sensitivitas dilakukan guna menguji ketidakpastian suatu investasi MKP yaitu apabila rendemen dari MPK turun karena menurunnya produksi daun yang kurang optimal akibat umur serta pemeliharaan tegakan tanaman kayu putih. 
Pengujian sensitivitas terhadap perubahan arus pengeluaran maupun penerimaan apabila produksi MKP turun $10 \%$ dan $15 \%$ dari kondisi produksi normal.

\section{Hasil dan Pembahasan}

\subsection{Analisis teknis pembuatan $M K P$}

Analisis teknis pembuatan MKP dengan potensi bahan baku MKP berupa daun tanaman kayu putih di Desa Cikembang dan potensi penyulingan MKP telah dilakukan, yaitu :

- Potensi penyulingan terpasang (Gambar 1) dengan metode sistem uap panas/steam, dapat menghasilkan kualitas minyak cukup baik, tekanan dan suhunya dapat diatur, waktu penyulingan pendek/singkat, minyak mempunyai titik didih tinggi, akan tetapi metode ini peralatannya cukup mahal (Nasional, 2006).

- Kondisi proses penyulingan sistem uap panas/steam terpasang: bahan baku dilayukan; pemasukan air guna pemasukan bahan; penimbangan bahan; pemasukan bahan, standar api pemanasan dengan bahan bakar kayu; rangkaian destilasi; proses hasil minyak selama 6-8 jam; tetesan pertama pada jam ke 4 dan proses pemanenan minyak atsiri kayu putih.

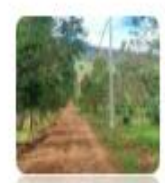

(a)

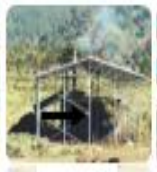

(b)

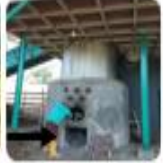

(c)

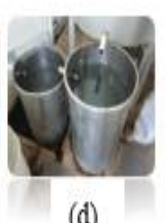

(d)
Gambar 1. Alur Proses Penyulingan Minyak Kayu Putih (MKP)

Analisis teknis pembuatan MKP secara rinci adalah :

a. Bahan baku kayu putih

Bahan daun kayu putih diperoleh di Desa Cikembang sebagai penghasil daun bahan baku MKP. Bahan baku menghasilkan rendemen minyak dari kebun kayu putih di Pulau Jawa berkisar antara 0,60 - 1,00 \%, sedang di Pulau Buru dan Pulau Seram rata-rata hanya sebesar $0,6 \%$ (Prastyono, Noor Khomsah Kartikawati, 2020).

\section{b. Mesin Proses penyulingan MKP}

Mesin penyulingan MKP dengan sistem kukus yang berlokasi di Kecamatan Kertasari, sangat memungkinkan untuk digunakan di lokasi bahan baku MKP dalam hal ini Desa Cikembang. Mesin tersebut memiliki standar yang dapat mendukung proses penyulingan.

\section{c. Proses penyulingan bahan baku MKP}

Proses produksi MKP dengan daun tanaman kayu putih dengan proses penyulingan menggunakan metode penyulingan uap dan air (Water and Steam Distillation)(Aryani, 2020).

\section{d. Produk MKP}

Produk MKP hasil proses produksi dengan sistem uap panas/steam. Rimbawano dan Susanto, 2002; (Astana et al., 2007) mengungkapkan dalam Proses penyulingan minyak kayu putih skala produksi sampai dengan skala pabrik merupakan pabrik padat karya yang dapat menyerap tenaga kerja yang cukup banyak, mulai dari kegiatan pemeliharaan tanaman, pemetikan daun sewaktu panen, kemudian tenaga kerja pada saat proses penyulingan, serta pengolahan limbah daun. Kegiatan pembuatan penyulingan MKP tersebut tentunya selaras dengan upaya perbaikan ekonomi masyarakat, serta petani yaitu dapat menyerap tenaga kerja. Kegiatan tersebut membentuk modal sosial di lingkungan pekerja minyak kayu putih berupa partisipasi aktif, kepercayaan, kerjasama serta hubungan timbal balik (Hamiru, Umanailo, Hehamahua, \& Hamid, 2019).

\section{e. Distilasi kukus skala laboratorium}

Distilasi kukus skala laboratorium (Gambar 2) dipilih yaitu untuk mengetahui apakah teknik penyulingan distilasi kukus memiliki rendemen tinggi (Helfiansah et al., 2013), pada penyulingan terpasang (Gambar 1).
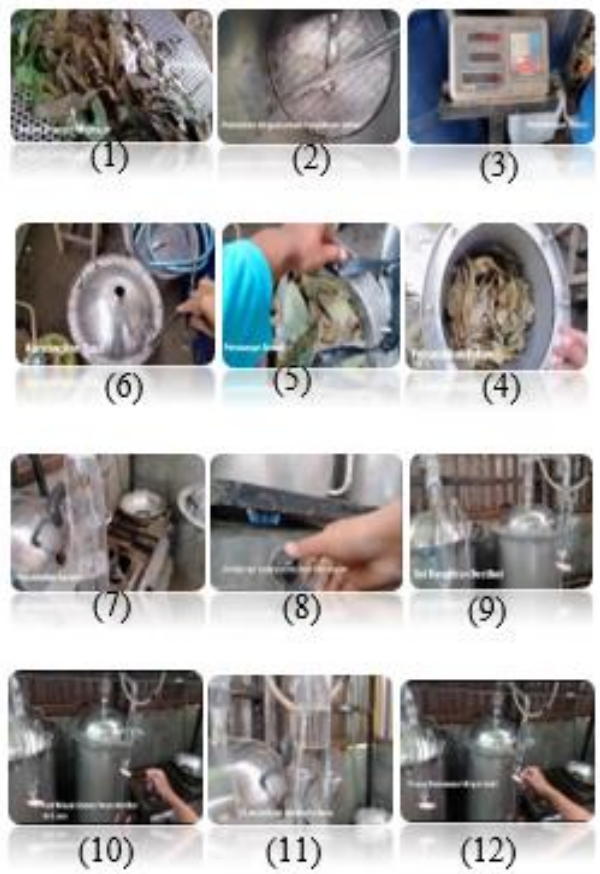

Gambar 2. Distilasi Kukus Skala Laboratorium 
Proses distilasi kukus pada gambar 2, dilakukan dengan proses antara lain: (1) bahan dianginanginkan; (2) pemasukan air guna pemasukan bahan; (3) penimbangan bahan; (4) pemasukan bahan (5) pemasangan sponati; (6) penutupan dan kencangkan baut; (7) penambahan akuades; (8) standar api sedang pada awal pemanasan; (9) set rangkaian destilasi; (10) proses hasil minyak selama 6-8 jam; (11) tetesan pertama pada jam ke 3; (12) proses pemanenan minyak atsiri kayu putih. Dari proses distilasi dapat disimpulkan bahwa minyak kayu putih yang dihasilkan memiliki potensi rendemen tinggi dengan ditandainya tetesan pertama pada 3 jam pertama. Warna jernih sesuai spesifikasi warna standar minyak atsiri kayu putih berwarna jernih, untuk bau minyak yang dihasilkan khas bau kayu putih dan bobot jenis 0,913 gr/ml masuk dalam spesifikasi standar rentang bobot jenis yang dipersyaratkan $0,900-0,930 \mathrm{gr} / \mathrm{ml}$.

\subsection{Analisis tekno ekonomi MKP}

Dalam perhitungan tekno ekonomi digunakan asumsi pengusahaan MKP selama umur usaha 15 tahun berdasarkan masa produktif, periode stabil produksi maksimum daun tanaman kayu putih pada umur tegakan yaitu 13 - 26 tahun (Utomo et al., 2012). Nilai jenis biaya antara lain biaya pengeluaran (outflow) yang terdiri dari: 1. biaya investasi: (a) persiapan lahan, (b) peralatan dan bahan penyulingan; 2. Biaya variabel produksi MKP; 3. Biaya tetap (biaya tenaga kerja, biaya penyusutan peralatan). Data outflow diperoleh dengan total Rp. 428.391.963,- yang terdiri dari biaya investasi Rp. 151.891.400; biaya variabel produksi MKP sebesar Rp.68.968.500,-; biaya tetap sebesar Rp. 29.725.232,-. Data analisis dengan asumsi harga pokok produksi Rp. 70.000,-/liter dengan kapasitas produksi 1.440 liter/tahun, untuk lahan kayu putih skala 1 hektar dengan sistem tanam MPS.

Analisis ini dilakukan terhadap pengusahaan MKP mulai dari biaya outflow tersebut dianalisis mulai dari biaya investasi persiapan lahan, peralatan dan bahan penyulingan (bahan bakar, bahan baku daun kayu putih, alat penyulingan, pemeliharaan, tenaga kerja dan transportasi). Hal ini dilakukan untuk menilai setiap biaya yang diperlukan, sebagaimana tujuan yaitu dapat menciptakan lapangan kerja baru (seperti tenaga pemeliharaan, pemanenan dan lain-lain), serta dapat menjadi model keberlanjutan dan kemandirian apabila program Citarum Harum selesai yang semula penyediaan bibit, pengelolaan lahan dibantu oleh Satgas Sektor 23 Citarum Harum.

Berdasarkan analisis data seperti yang disajikan pada tabel 1 dan 2, terlihat bahwa pengusahaan MKP skala produksi dengan kapasistas 1.440 liter/per tahun daun tanaman kayu putih skala satu hektar layak untuk dijalankan secara komersial. Nilai kelayakan tersebut dapat dilihat dari nilai Internal Rate of Rerurn (IRR) yaitu sebesar 22,5\% lebih besar dari tingkat bunga bank yang diaplikasikan pada analisis tersebut dengan diskonto 5,65\%. Dapat dilihat lebih jauh pula bahwa pengusahaan MKP akan Kembali modal dalam jangka waktu 6.31 tahun atau setara dalan jangka waktu 76 Bulan.

Tabel 1.

Ringkasan analisis tekno ekonomi pengusahaan MKP skala produksi (Analisa pengusahaan selama 15 tahun)

\begin{tabular}{ccc}
\hline No & Parameter & Nilai \\
\hline 1 & Kapasitas inflow MKP & 1.440 \\
& (liter/tahun) & \\
2 & Total inflow & 1.077 .107 .472 \\
3 & Biaya investasi & 151.891 .400 \\
4 & Biaya vaeriabel produksi & 68.968 .500 \\
5 & Biaya Tetap & 29.725 .232 \\
6 & Total outflow sblm pajak & 402.476 .532 \\
7 & Pajak 12\% & 25.915 .431 \\
8 & Total outflow & 428.391 .963 \\
9 & Net Benefit & 648.715 .509 \\
\hline
\end{tabular}

Berdasarkan data pada Tabel 2, disampaikan bahwa pengusahaan MKP skala produksi ini memiliki nilai BEP pada Rp. 32.072.769,- dengan kata lain usaha tersebut tidak akan untung dan tidak akan rugi pada saat pendapatan di posisi titik impas mencapai Rp. 32.072.769,--. Agar pengusahaan MKP mempunyai keuntungan harus memproduksi MKP rata-rata 1.440 liter per tahun atau setara dengan $20 \%$ kapasitas pada BEP.

Tabel 2.

Ringkasan analisis parameter kalayakan pengusahaan MKP (Analisa pengusahaan selama 15 tahun)

\begin{tabular}{ccc}
\hline No & Parameter & Nilai \\
\hline 1 & NVP (diskonto 5,65 \%) (Rp) & 323.302 .615 \\
2 & IRR (\%) & 22,5 \\
3 & Payback period (Tahun / bulan) & $6,31 / 76$ \\
4 & Harga pokok produksi (Rp) & 70.000 \\
5 & Break event point (BEP) (Rp) & 32.072 .769 \\
6 & Persentase pada BEP (\%) & 20 \\
7 & Kapasitas pada BEP & 1.440 \\
& (Liter/tahun) \\
\hline
\end{tabular}

\subsection{Analisis sensitivitas investasi pengusahaan MKP}

Untuk melihat resiko investasi pengusahaan MKP, maka dilanjutkan dengan analisis sensitivitas. Hasil analisis sensitivitas dapat dilihat pada Tabel 3 dan 4 . Sesuai analisis sensitivitas yang disajikan pada tabel 3 dan tabel 4 terlihat bahwa parameter biaya yang paling sensitif berpengaruh terhadap nilai kelayakan yaitu rendemen bahan baku MKP dan jumlah hari kerja dalam setahun. Hal tersebut ditandainya oleh penurunan produksi MKP nilai NPV dari pengusahaan MKP. Penurunan produksi MKP sebesar $10 \%$ dan $15 \%$ dilakukan sebagai analisis sensitivitas terhadap stategi pengusahaan MKP di Desa Cikembang, apabila terdapat penurunan 
produksi bahan baku MKP berupa daun mulai tanaman.

Pengusahaan MKP dengan sensitivitas 10\% (tabel 3) diperoleh nilai NPV sebesar Rp. 278.180.928,-, dengan IRR : 22,5\%; payback period : 6,64 tahun atau 80 bulan. Adapun harga pokok produksi MKP relatif stabil sesuai kondisi normal yaitu Rp. 70.000,dengan BEP: Rp.32.167.873,-. Kemudian persentase pada BEP: 19\% (untuk analisa pengusahaan MKP selama 15 Tahun), serta kapasitas produksi MKP pada 1.296 liter/tahun pada BEP.

Tabel 3.

Hasil analisis sensitivitas pengusahaan MKP dengan produksi mengalami penurunan $10 \%$

\begin{tabular}{ccc}
\hline No & Parameter & Nilai \\
\hline 1 & NVP (diskonto 5,65 \%) (Rp) & 279.180 .928 \\
2 & IRR (\%) & $22,5 \%$ \\
3 & Payback period (Tahun / bulan) & $6,64 / 80$ \\
4 & Harga pokok produksi (Rp) & 70.000 \\
5 & Break event point (BEP) (Rp) & 32.167 .873 \\
6 & Persentase pada BEP (\%) & 19 \\
7 & Kapasitas pada BEP & 1.296 \\
& (Liter/tahun) \\
\hline
\end{tabular}

Analisis sensitivitas pengusahaan MKP sebesar 15\% (tabel 4) diperoleh nilai NPV sebesar Rp. 234.700.609,-; dengan nilai IRR : 22,5\%; untuk payback period 6,84 tahun atau 82 bulan. Adapun harga pokok produksi MKP sebesar Rp. 70.000,-; dengan nilai BEP selama umur analisis kelayakan pengusahaan MKP yaitu sebesar Rp. 32.407.406,atau sebesar $16 \%$, dengan kapasitas produksi 1.224 (dengan analisis penurunan kapasitas produksi sebesar 15\%).

Tabel 4.

Hasil analisis sensitivitas pengusahaan MKP dengan produksi mengalami penurunan $15 \%$

\begin{tabular}{ccc}
\hline No & Parameter & Nilai \\
\hline 1 & NVP (diskonto 5,65 \%) (Rp) & 234.700 .609 \\
2 & IRR (\%) & 22,5 \\
3 & Payback period (Tahun / bulan) & $6,84 / 82$ \\
4 & Harga pokok produksi (Rp) & 70.000 \\
5 & Break event point (BEP) (Rp) & 32.407 .406 \\
6 & Persentase pada BEP (\%) & 16 \\
7 & Kapasitas pada BEP & 1.224 \\
& (Liter/tahun) \\
\hline
\end{tabular}

\section{Kesimpulan}

Minyak kayu putih (MKP) diperoleh dari proses penyulingan dengan proses steam/uap mempunyai kelebihan waktu proses yang relatif cepat dan produk MKP. Dari proses distilasi dapat disimpulkan minyak kayu putih yang dihasilkan memiliki potensi rendemen tinggi dengan ditandainya tetesan pertama pada 3 jam pertama. Warna jernih sesuai spesifikasi warna standar minyak atsiri kayu putih berwarna jernih, untuk bau minyak yang dihasilkan khas bau kayu putih dan bobot jenis 0,913 gr/ml masuk dalam spesifikasi standart rentang bobot jenis yang dipersyaratkan 0,900 - 0,930 gr/ml. Hal tersebut menguntungkan karena pengusahaan minyak kayu putih (MKP) sebagai alternatif pasca panen di Desa Cikembang memiliki potensi yang layak dilakukan, sebagai pendukung sistem MPTS (Multy Puporse Tree Spesies) yaitu sistem tanam dalam satu lahan ditanami 3 (tiga) jenis tanaman penghasil daun sebagai bahan baku MKP skala produksi. Selanjutnya untuk analisis tekno ekonomi ditunjukkan bahwa pengusahaan MKP layak dijalankan dengan beberapa parameter yaitu NPV sebesar Rp. 323.302.615,-; nilai IRR: 22,5\% dan pay back period (PB) 6,31 tahun atau 76 bulan. Sesuai analisis sensitivitas, pengusahaan MKP tersebut sangat sensitif terhadap parameter menurunnya jumlah produksi bahan baku MKP yaitu daun tanaman kayu putih. Demikian juga investasi berupa penyulingan MKP baru dengan sistem uap panas/steam sejenis peralatan penyulingan di Kecamatan Kertasari untuk penyulingan layak dilakukan.

\section{Ucapan Terima Kasih}

Penulis ucapkan terima kasih banyak Kepada Bapak Prakoso Bhairawa Putera, S.IP., M.A., (Kepala BPK LIPI), Bapak Danang Heru Prasetyo, M.Sc., Bapak Poerwanto Soeseno, SE. MM. dan tim di Fungsi Monitoring Evaluasi BPK LIPI Kawasan Bandung, pengelola program By-Research LIPI, Komandan Sektor Satgas Ciatrum Harum/Bapak Kolonel Arh. Wahyu J, beserta jajarannya, Reza Nugraha (pendamping Gapoktan Desa Cikembang) atas dukungan yang diberikan selama ini.

\section{Daftar Pustaka}

Alamsyah, R., \& Supriatna, D. (2018). Analisis teknik dan tekno ekonomi pengolahan biomassa limbah tandan kosong kelapa sawit ( TKKS ) menjadi pelet sebagai bahan bakar terbarukan skala produksi pellet as renewa. Warta IHP/ Journal of Agro-Based Industry, 35(1), 1-11.

Aryani, F. (2020). Penyulingan minyak kayu putih (Melaleuca cajuputi) dengan Suhu yang berbeda. Buletin LOUPE, 16(02), 51-57.

Astana, S., Djaenudin, D., Parlinah, N., \& Suka, A. P. (2007). Analisis distribusi margin tataniaga minyak kayu putih. Jurnal Penelitian Sosial Dan Ekonomi Kehutanan, 4(3), 205-219. https://doi.org/10.20886/jpsek.2007.4.3.205219

Behuku, W. M., Kastanya, A., \& Pattimahu, D. V. (2016). Analisis nilai tambah ekonomi (economy value added) untuk mengukur kinerja keuangan petani minyak kayu putih Desa Pela dan BATU JUNGKU di wilayah kerja kesatuan pengelolaan hutan produksi (KPHP) 
model unit III WAE TINA. Jurnal Hutan PulauPulau Kecil,1(1), 66-71. https://doi.org/10.30598/jhppk.2016.1.1.66

[BSN] Badan Standardisasi Nasional. (2006). Standar Nasional Indonesia Minyak Kayu Putih SNI 06-3954-2006. Jakarta: Badan Standardisasi Nasional.

Hamiru, Umanailo, M. C. B., Hehamahua, H., Hamid, I. (2019). Modal Sosial Pekerja Minyak Kayu Putih di Desa Waplau. Jurnal Ilmu Sosial Dan Ilmu Politik, 9(2), 109-124.

Indrajaya, Y., Winara, A., Siarudin, M., Junaidi, E., \& Widiyanto, A. (2013). Analisis kelayakan finansial pengusahaan minyak kayu putih tradisional di taman nasional wasur, papua (financial feasability analysis of traditional cajuput oil refinery in wasur national park, papua). Penelitian Sosial Dan Ekonomi Kehutanan, 10(1), 21-32.

Kementerian Kehutanan. (2014). Budidaya dan prospek pengembangan kayu putih (Melaleuca cajuputi) (pp. 1-44). Jakarta: IPB Press.

Limam, H., Ben, M., Tammar, S., Ksibi, N., Khammassi, S., Jallouli, S., Del, G., \& Msaada, K. (2020). Variation in chemical profile of leaves essential oils from thirteen Tunisian Eucalyptus species and evaluation of their antioxidant and antibacterial properties. Industrial Crops \& Products, 158(September), 112964. https://doi.org/10.1016/j.indcrop.2020.1129 64

Ma'mun. (2015). Petunjuk Teknis Penanganan Bahan dan Penyulingan Minyak Atsiri. In Sirkuler Informasi Teknologi Tanaman Rempah dan Obat (pp. 1-26). Bogor: Balai Penelitian Tanaman Rempah dan Obat.

Menteri Kehutanan. (2007). Peraturan Menteri Kehutanan Nomor: P.35/ Menhut-II/ 2007 Tentang Hasil Hutan Bukan Kayu. Jakarta: Menteri Kehutanan.

Menteri Negara Sekretaris Negara Republik Indonesia. (1999). Peraturan Pemerintah Republik Indonesia Nomor 6 Tahun 1999 Tentang Pengusahaan Hutan dan Pemungutan Hasil Hutan Pada Hutan Produksi. Jakarta: Menteri Negara Sekretaris Negara Republik Indonesia.

Mohhamad dan Etty. (2017). Kelayakan agroindustri minyak kayu putih di Kota Tarakan. Journal of Chemical Information and Modeling, 110(9), 17-20.

Nasution, M. K. (2014). Potensi hasil hutan bukan kayu sebagai sumber pencapatan negara. Acameia Accelerating the World's Research, 115.

Prastyono, Kartikawati, N. K., Sumardi, \& Rimbawanto, A. (2020). Analisis finansial perkebunan kayu putih skala kecil: studi kasus pilot project pengembangan kayu putih untuk kelompok tani di Kampung Rimbajaya, Distrik Biak Timur. Jurnal Ilmu Kehutanan, 14(1), 315.

Purhantanto, L. N., Danoedoro, P., \& Wicaksono, P. (2019). Kajian transformasi indeks vegetasi citra satelit sentinel-2a untuk estimasi produksi daun kayu putih menggunakan linear spectral mixture analysis. Jurnal Nasional Teknologi Terapan, 3(1), 47-70.

Rahmi, D. (2018, April 17). Minyak Atsiri Indonesia dan Peluang Pengembangannya. Balai Besar Kimia Dan Kemasan [online]. Diakses pada 30 Agustus 2021 dari http://bbkk.kemenperin.go.id/Page/Bacaartik el.Php?Id=0SCDT7v3kb042NmtwHDAEGAxVG 96ARtA072jn2iwylQ

Sari, P. W. dan Ratnaningsih, Y. (2020). Analisis pendapatan petani HHBK kayu putih (Melaleuca cajuputi) di hutan lindung Desa Montong Sapah Kecamatan Praya Barat Daya Kabupaten Lombok Tengah. Jurnal Silva Samalas, 3(1), 7-14.

Utomo, P. M., Suhendang, E., Syafii, W., \& Simangunsong, B. C. H. (2012). Model produksi daun pada hutan tanaman kayu putih (Melaleuca cajuputi subsp cajupti. POWELL) sistem pemanenan pangkas tunas. Jurnal Penelitian Hutan Tanaman, 9(4), 195-208. https://doi.org/10.20886/jpht.2012.9.4.195208 